\title{
Influence of the epiretinal membrane on ranibizumab therapy outcomes in patients with diabetic macular edema
}

\author{
Influência da membrana epirretiniana sobre os resultados da terapia de ranibizumab \\ em edema macular diabético
}

Nimet Yesim Ercalik ${ }^{1}$, Serhat Imamoglu ${ }^{1}$, Esra Turkseven Kumral ${ }^{1}$, Nursal Melda Yenerel ${ }^{1}$, Handan Bardak ${ }^{1}$, Yavuz Bardak $^{1}$

\begin{abstract}
Purpose: To investigate the influence of the epiretinal membrane (ERM) on intravitreal ranibizumab (IVR) therapy for diabetic macular edema (DME).

Methods: This retrospective study included 56 eyes of 48 patients with DME divided into two groups: the DME with ERM (study) and only DME (control) groups. Changes in the central macular thickness (CMT) and best-corrected visual acuity (BCVA) were evaluated.

Results: In the study group, although the CMT was significantly reduced following the first injection $(p<0.001)$, BCVA did not improve significantly $(p=0.296)$. However, after the first injection, the control group exhibited both a significant decrease in CMT $(p<0.001)$ and improvement in BCVA $(p<0.001)$. However, the improvement in BCVA in the control group was not significantly different from the outcome of the study group.
\end{abstract}

Conclusions: We observed a negative short-term influence of the ERM on IVR treatment for DME.

Keywords: Epiretinal membrane; Macular edema; drug therapy; Retinopathy; diabetic complications; Ranibizumab/therapeutic use

\section{RESUMO}

Objetivo: Investigar a influência da membrana epirretiniana (ERM) na terapia intravitrea com ranibizumab (IVR) para o edema macular diabético (DME).

Métodos: Este estudo retrospectivo consistiu de 56 olhos de 48 pacientes com DME que foram divididos em dois grupos: o grupo DME com ERM (estudo) e o grupo só DME (controle). Foram avaliadas alterações na espessura central de macular (CMT) e melhor acuidade visual corrigida (BCVA).

Resultados: No grupo de estudo, embora a CMT tenha sido significativamente reduzida após a 1 injeção $(p<0,001)$, a acuidade visual não melhorou significativamente $(p=0,296)$. Após a 1a injeção, o grupo controle apresentou diminuição significativa no $\operatorname{CMT}(p<0,001)$ e melhora na acuidade visual $(p<0,001)$. No grupo controle, embora a mudança de CMT tenha sido significativa ( $p<0,001)$, a melhora da acuidade visual não foi significativa quando comparada com o grupo de estudo.

Conclusões: No curto prazo, observou-se uma influência negativa da ERM sobre o IVR em DME.

Descritores: Membrana epirretiniana; Edema macular/quimioterapia; Retinopatia diabética/complicações; Ranibizumab/uso terapêutico

\section{INTRODUCTION}

Diabetic macular edema (DME) is the most common cause of decreased visual acuity (VA) in patients with diabetes mellitus ${ }^{(1)}$, and has been associated with vitreomacular interface abnormality (VMIA) incidence rates of 7\%-16\%(2,3). Currently, anti-vascular endothelial growth factor (VEGF) agents are considered gold-standard agents in the management of DME and have been shown to improve clinical outcomes ${ }^{(4)}$. However, the presence or absence of VMIAs could potentially affect responses to anti-VEGF treatment in patients with DME; specifically, these agents may be less effective in patients with VMIAs ${ }^{(5,6)}$

Vitreomacular traction (VMT) may cause low-grade inflammation and stimulate the induction or progression of DME by inducing the continued release of VEGF, a powerful angiogenic and vascular permeability factor ${ }^{(7,8)}$. Interleukin-6 (IL-6), an inflammatory cytokine with various biological effects, is expressed in the vitreous fluid and retinal tissue and plays a critical role in the pathophysiologic process of diabetic retinopathy ${ }^{(9)}$. Recent studies have shown that IL-6 induces the expression of VEGF, the most important primary mediator of retinal angiogenesis ${ }^{(10,11)}$. VEGF and its receptors, as well as IL-6, localize to cells in the vascular and avascular epiretinal membranes (ERMs) of patients with diabetic retinopathy, thus further increasing inflammation ${ }^{(12,13)}$ and possibly promoting persistent DME. Although patients with ERM likely require more frequent injections for inflammation, ERMs may act as a physical barrier and decrease drug penetration.

The present study investigated the effects of ERM on visual acuity and morphological changes in patients with DME who are receiving intravitreal ranibizumab (IVR) therapy.

\section{METHODS}

This retrospective comparative study included 56 eyes of 48 patients with DME who received IVR therapy at the Research and Training Hospital, İstanbul, Turkey between 2012 and 2015. Patients were divided into a study group (DME with ERM) or control group (only DME). Informed consent was obtained from all patients before receiving IVR therapy. This study, which followed the tenets of the Declaration of Helsinki, was conducted after receiving ethics committee approval.
Funding: No specific financial support was available for this study.

Disclosure of potential conflicts of interest: None of the authors have any potential conflicts of interest to disclose.

Corresponding author: Serhat Imamoglu. Tıbbiye Cad, № 40 - Üsküdar - Istanbul, 34668 - Turkey E-mail: ophserhat@hotmail.com

Approved by the following research ethics committee: Haydarpasa Numune Training and Research Hospital. 
The study inclusion criteria included the following: (1) the presence of clinically significant DME on a fundus examination; (2) presence of angiographically confirmed DME; (3) presence of DME and ERM documented by optical coherence tomography (OCT); and (4) central macular thickness (CMT) > $300 \mu \mathrm{m}$ on OCT. The exclusion criteria were (1) previous vitreoretinal surgery; (2) loss of vision from causes other than DME and ERM; (3) intravitreal injection of bevacizumab, ranibizumab, or steroids and/or laser treatments within the previous 3 months; and (4) a follow-up duration $<3$ months. All patients underwent a complete eye examination that included best corrected visual acuity (BCVA) measurements (Snellen's chart), slit-lamp biomicroscopy, indirect ophthalmoscopy, intraocular pressure (IOP) measurement (Goldmann applanation tonometry), fluorescein angiography (FFA; Visucam500, Carl Zeiss Meditec, Jena, Germany), and spectral-domain OCT (RTVue-100; Optovue Inc., Fremont, CA, USA). The primary outcome measures were changes in the CMT and BCVA. On OCT, ERMs were recognizable as thin, hyperreflective bands anterior to the retina.

All injections were conducted under sterile conditions in an operating room. Eyes were anesthetized with topical $0.5 \%$ proparacain hydrochloride, and 5\% povidone iodine was used for endophthalmitis prophylaxis. Subsequently, a 0.5 -mg IVR injection (Lucentis; Novartis Pharma AG, Basel, Switzerland and Genentech, Inc., South San Francisco, CA, USA) was administered the superotemporal pars plana (4 mm posterior to the limbus) using a 30-gauge needle. Topical $0.3 \%$ ofloxacin eye drops were prescribed 4 times daily for 5 days after the injection. Follow-up examinations were scheduled for the first day, first week, and first, second, and third months postoperatively. BCVA and OCT examinations were performed at the first-, second-, and third-month follow-ups.

Statistical analyses were performed using SPSS software version 16 for Windows (SPSS Inc., Chicago, IL, USA). Variables were investigated using both visual (histograms, probability plots) and analytical methods (Kolmogorov-Simirnov, Shapiro-Wilk test) to determine normal or abnormal distribution. Because the BCVA and CMT were not normally distributed, the nonparametric Friedmann test was used to determine the significance of changes in BCVA and CMT. $\mathrm{BCVAs}$ were converted to the logarithm of minimal angle of resolution (logMAR) format for statistical manipulation.

Serial comparisons of pre- and post-treatment outcomes were performed using the Wilcoxon matched pairs nonparametric test. The Mann-Whitney U test was used to compare variables between the groups. Cross-tabulation was used to present the frequencies of patients in both groups according to sex and the presence of diabetic retinopathy. The chi-square test or Fisher's exact test (when chi-square test assumptions did not hold because of low expected cell counts) was used to compare these frequencies among different groups. A $p$ value $<0.05$ was considered to show a statistically significant result.

\section{RESULTS}

The demographic and clinical characteristics of both groups are summarized in table 1 . The study group patients were significantly older than the control group patients $(p=0.037)$. However, the groups did not differ with respect to sex, diabetes status, and diabetes duration.

Changes in the logMar BCVA and CMT from baseline after the first injection are shown in table 2. Patients in the study group had a significantly worse baseline BCVA $(0.71 \pm 0.27$ logMAR vs. $0.46 \pm 0.21$ $\log M A R$ in the control group; $\mathrm{p}=0.001)$. Although the groups did not differ significantly in terms of BCVA improvement at the first-month follow-up, only the control group achieved a statistically significant difference from the baseline.

The mean baseline CMT values were $422.1 \pm 82.8 \mu \mathrm{m}$ in the study group and $439.5 \pm 71.4 \mu \mathrm{m}$ in the control group, and this difference was not significantly different $(p=0.357)$. Both groups, however, experienced a significant decrease in CMT at the postoperative first-month
Table 1. Baseline characteristics of 56 eyes from 48 patients with diabetic macular edema

\begin{tabular}{lccc}
\hline & Control & Study & P value \\
\hline No of patients & 27 & 21 & \\
Age $( \pm \mathrm{SD})$, years & $60.2 \pm 7.5$ & $65.4 \pm 6.7$ & $0.037^{*}$ \\
Sex (male/female) & $15 / 12$ & $15 / 6$ & $0.260^{*}$ \\
Duration of DM (years $\pm \mathrm{SD})$ & $10.8 \pm 5.3$ & $12.4 \pm 6.1$ & $0.300^{*}$ \\
Stage (NPDR/PDR) & $24 / 6$ & $17 / 9$ & $0.210^{*}$ \\
\hline${ }^{*}=$ statistically significant; $\mathrm{SD}=$ standard deviation; $\mathrm{DM}=$ diabetes mellitus; $\mathrm{NPDR}=$ nonpro-
\end{tabular}

liferative diabetic retinopathy; $\mathrm{PDR}=$ proliferative diabetic retinopathy.

Table 2. Change in logMAR best corrected visual acuity (BCVA) and central macular thickness (CMT) from baseline after one injection

\begin{tabular}{lccc}
\hline & Control & Study & P value \\
\hline Baseline BCVA & $0.46 \pm 0.21$ & $0.71 \pm 0.27$ & \\
Post injection BCVA & $0.35 \pm 0.21$ & $0.68 \pm 0.29$ & \\
P value (1 $1^{\text {st }}$ month frombaseline) & $<0.001^{1}$ & $0.296^{2}$ & $0.001^{3}$ \\
Baseline CMT & $439.5 \pm 71.4$ & $422.1 \pm 82.8$ & \\
Post injection CMT & $325.3 \pm 65.4$ & $363.1 \pm 78.2$ & \\
P value (1 ${ }^{\text {st }}$ month frombaseline) & $<0.001^{1}$ & $<0.001^{2}$ & $0.357^{3}$ \\
\hline
\end{tabular}

${ }^{1}=$ baseline vs $1^{\text {st }}$ injection in control group; ${ }^{2}=$ baseline vs $1^{\text {st }}$ injection in study group;

$3=$ baseline control vs patient groups.

follow-up $(p<0.001)$. In contrast to the BCVA, the decreases in the mean CMT after the first injection also differed significantly between the groups $(58 \mu \mathrm{m}$ in the study group vs. $114 \mu \mathrm{m}$ in the control group, $p=0.002$ )

No remarkable elevations or significant changes in the IOP from the baseline were observed in either group, and none of the patients experienced injection-related complications. No changes in the features of the ERM were observed during the treatment procedure.

\section{DISCUSSION}

The present study investigated the effects of ERM on visual acuity and morphological changes in patients receiving IVR therapy for DME. In brief, we found that patients with ERM did not respond as well to IVR treatment as did those with only DME.

Pars plana vitrectomy (PPV) was commonly found to be beneficial in eyes with diffuse VMT-associated DME ${ }^{(14,15)}$. However, the use of PPV in such eyes can lead to complications and might also affect anti-VEGF treatment by reducing the half-lives of intravitreal anti-VEGF drugs; as a result, higher doses and more frequent injections of anti-VEGF drugs might be needed postoperatively ${ }^{(16,17)}$.

Although rare, the spontaneous resolution of VMT after IVR has been reported in patients with $D M E^{(18)}$. The potential for vitreous liquefaction and mechanical increase of in the vitreous volume after IVR injection might promote separation of the ERM. Accordingly, an initial approach in some cases of DME associated with ERM might include a few injections of anti-VEGF agents. However, such patients exhibit a decreased response to anti-VEGF therapy. Previously, VMIAs were found to associate with the use of intravitreal anti-VEGF agents in cases of persistent DME ${ }^{(5,6)}$. Wu et al. suggested that DME with VMIAs may correlate with a poor outcome after anti-VEGF treatment; however, the authors of that study followed patients who received only a single 1.25 -mg injection of bevacizumab during a 3-month study period ${ }^{(5)}$. Yoon et al. studied whether the administration of 3 anti-VEGF injections (either $0.3 \mathrm{mg}$ ranibizumab or $1.25 \mathrm{mg}$ bevacizumab) would affect BCVA and CMT in patients with DME with 
VMIAs, and observed that significantly reduced improvements in the BCVA of patients with both DME and VMIAs, compared to those with only $\mathrm{DME}^{(6)}$.

Our study differs from the two above-mentioned studies because we administered $0.5 \mathrm{mg}$ of ranibizumab to all patients, and only included patients with ERMs in our study group. We found that although the CMT was significantly reduced following IVR injection, the BCVA did not improve significantly in the study group, whereas the control group showed significant improvements both CMT and BCVA. In the study group, the limited response to IVR injection might indicate the inhibited perfusion of ranibizumab into the retina as result of the barrier effect of ERM, as well as chronic vitreomacular traction. In our study group, IVR therapy reduced the mean CMT in the first month, but yielded only a minimal and non-significant improvement in BCVA. This reduction in CMT appears to be related to a decrease in macular edema and is presumably related to the effect of ranibizumab on vascular permeability. The discrepancy between the decrease in CMT and increase in BCVA could be attributed to the previously mentioned factors. We observed that patients with ERM did not respond as strongly to IVR injections as did the control group in terms of the study outcome measures. However, we note that patients with ERM had a significantly worse baseline BCVA, which might have contributed to the lack of significant improvement in BCVA. We note that with regard to the baseline characteristics, the only other inter-group difference was in age. Specifically, the study group patients were significantly older than the control group patients, and the differences in outcomes may also be attributable to the finding that increasing age is a risk factor for ERMs ${ }^{(19)}$.

We note that our study was limited by a retrospective design, small number of patients, limited number of injections, lack of ERM pattern (partially or globally adherent) and quantitative ERM measurement, and the difference in the mean age between the two groups. Despite these limitations, our study demonstrated that patients with ERM did not respond as well to IVR treatment as did those with only DME. Despite the limited response to IVR therapy in cases with ERM, at least one IVR injection can be considered prior to a decision regarding PPV. In addition, the spontaneous resolution of ERM, although rare, should be kept in mind. Further studies will facilitate an understanding of the effects of ERM on anti-VEGF agent dosing strategies and the course of DME.

\section{REFERENCES}

1. Otani T, Kishi S, Maruyama Y. Patterns of diabetic macular edema with optical coherence tomography. Am J Ophthalmol.1999;127(6):688-93.
2. Chang $\mathrm{CK}$, Cheng $\mathrm{CK}$, Bai $\mathrm{CH}$, Peng $\mathrm{CH}$, Hu CC. Development of vitreomacular interface abnormality in patients with diabetic macular edema. Taiwan J Ophthalmol. 2012; 2(3):93-8.

3. Kim NR, Kim YJ, Chin HS, Moon YS. Optical coherence tomographic patterns in diabetic macular oedema:prediction of visual outcome after focal laser photocoagulation. Br J Ophthalmol. 2009;93(7):901-5.

4. Mitchell P, Wong TY, Diabetic Macular Edema Treatment Guidline Working Group. Management paradigms for diabetic macular edema. Am J Ophthalmol. 2014;157(3): 505-13.

5. Wu PC, Lai CH, Chen CL, Kuo CN. Optical coherence tomographic patterns in diabetic macula edema can predict the effects of intravitreal bevacizumab injection as primary treatment. J Ocul Pharmacol Ther. 2012;28(1):59-64.

6. Yoon D, Rusu I, Barbazetto I. Reduced effect of anti-vascular endothelial growth factor agents on diabetics with vitreomacular interface abnormalities. Int Ophthalmol. 2014; 34(4):817-23.

7. Schepens $C L$, Avila MP, Jalkh AE, Trempe CL. Role of the vitreous in cystoid macular edema. Surv Ophthalmol. 1984;28 Suppl:499-504.

8. Seko $Y$, Seko $Y$, Fujikura H, Pang J, Tokoro T, Shimokawa H. Induction of vascular endothelial growth factor after application of mechanical stress to retinal pigment epithelium of the rat in vitro. Invest Ophthalmol Vis Sci.1999;40(13):3287-91.

9. Kojima S, Yamada T, Tamai M. Quantitative analysis of interleukin-6 in vitreous from patients with proliferative vitreoretinal diseases. Jpn J Ophthalmol. 2001;45(1):40-5.

10. Cohen T, Nahari D, Cerem LW, Neufeld G, Levi BZ. Interleukin 6 induces the expression of vascular endothelial growth factor. J Biol Chem. 1996;271(2):736-41.

11. Aiello LP, Avery RL, Arrigg PG, Keyt BA, Jampel HD, Shah ST, et al. Vascular endothelial growth factor in ocular fluid of patients with diabetic retinopathy and other retinal disorders. N Engl J Med. 1994;331(22):1480-7.

12. Yamamoto T, Akabane N, Takeuchi S. Vitrectomy for diabetic macular edema: the role of posterior vitreus detachment and epimacular membrane. Am J Ophthalmol. 2001; 132(3):369-77.

13. Chen YS, Hackett SF, Schoenfeld CL, Vinores MA, Vinores SA, Champochiaro PA. Localisation of vascular endothelial growth factor and its receptors to cells of vascular and avascular epiretinal membranes. Br J Ophthalmol.1997:81(10):919-26.

14. Massin P, Duguid G, Erginay A, Haouchine B, Gaudric A. Optical coherence tomography for evaluating diabetic macular edema before and after vitrectomy. Am J Ophthalmol. 2003:135(2):169-77.

15. Song SJ, Sohn JH, Park KH. Evaluation of the efficacy of vitrectomy for persistent diabetic macular edema and associated factors predicting outcome. Korean J Ophthalmol. 2007;21(3):146-50.

16. Christoforidis JB, Xie Z, Jiang A, Wang J, Pratt C, Gemensky-Metzler A, et al. Serum levels of intravitreal bevacizumab after vitrectomy, lensectomy and non-surgical controls. Curr Eye Res. 2013;38(7):761-6.

17. Yanyali A, Aytug B, Horozoglu F, Nohutcu AF. Bevacizumab (Avastin) for diabetic macular edema in previously vitrectomized eyes. Am J Ophthalmol. 2007;144(1):124-6.

18. Rouvas A, Petrou P, Ladas I, Neamonitou G, Vergados I. Spontaneous resolution of vitreomacular traction following ranibizumab (Lucentis) injection. Eur J Ophthalmol. 2008; 18(2):301-3.

19. $\mathrm{Ng} \mathrm{CH}$, Cheung N, Wang JJ, Islam AF, Kawasaki R, Meuer SM, et al. Prevalence and risk factors for epiretinal membranes in a multi-ethnic United States population. Ophthalmology. 2011;118(4):694-9. 